University of Wollongong

Research Online

Faculty of Engineering and Information

Faculty of Engineering and Information

Sciences - Papers: Part A

Sciences

$1-1-2016$

Developing an optimum maintenance policy by life cycle cost analysis - a case study

Khaled O. El-Akruti

University of Wollongong, khaled@uow.edu.au

Tieling Zhang

University of Wollongong, tieling@uow.edu.au

Richard Dwight

University of Wollongong, radwight@uow.edu.au

Follow this and additional works at: https://ro.uow.edu.au/eispapers

Part of the Engineering Commons, and the Science and Technology Studies Commons

Research Online is the open access institutional repository for the University of Wollongong. For further information contact the UOW Library: research-pubs@uow.edu.au 


\title{
Developing an optimum maintenance policy by life cycle cost analysis - a case study
}

\begin{abstract}
This paper focuses on developing maintenance policies for critical assets to improve the production performance based on life cycle cost (LCC) analysis. A general approach is adopted for conducting the LCC analysis. The investigation is based on a case study to demonstrate how an optimum maintenance policy is determined. The relevant LCC structure in the case study is defined for the decision process which involves determination of the optimum life, repair limit and selection of materials, and trade-off between repair and replacement. The LCC analysis is based on statistical data modelling which facilitates decision-making on the optimal replacement of an asset and its remaining life. Based on the optimization and remaining life criterion, the optimal maintenance policy can be made. The results obtained from this case study include selection of the best lining material for use, determination of the optimal time for refractory lining replacement, the hot repair sequence required for maintaining the optimum condition and the repair limit for doing cold repairs before replacement, for one type of electric arc furnaces used in the steel industry.
\end{abstract}

\section{Keywords}

optimum, maintenance, policy, developing, life, study, cycle, cost, analysis, case

\author{
Disciplines \\ Engineering | Science and Technology Studies
}

\section{Publication Details}

El-Akruti, K., Zhang, T. \& Dwight, R. (2016). Developing an optimum maintenance policy by life cycle cost analysis - a case study. International Journal of Production Research, 54 (19), 5946-5962. 


\section{Pristions Production Research

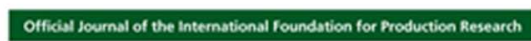

\section{Developing an Optimum Maintenance Policy by Life Cycle Cost Analysis -- A Case Study}

\begin{tabular}{|r|l|}
\hline Journal: & International Journal of Production Research \\
\hline Manuscript ID & TPRS-2015-IJPR-0747.R2 \\
\hline Manuscript Type: & Original Manuscript \\
\hline Complete List of Authors: & $\begin{array}{l}\text { El-Akruti, Khaled; University of Wollongong, } \\
\text { Zhang, Tieling } \\
\text { Dwight, Richard; University of Wollongong, }\end{array}$ \\
\hline Keywords: & $\begin{array}{l}\text { MAINTENANCE MANAGEMENT, MAINTENANCE PLANNING, COST ANALYSIS, } \\
\text { PRODUCTION MANAGEMENT, LIFE CYCLE MANAGEMENT }\end{array}$ \\
\hline Keywords (user): & Maintenance Policies, LIFE CYCLE COST \\
\hline \multicolumn{2}{|c}{} \\
\hline
\end{tabular}




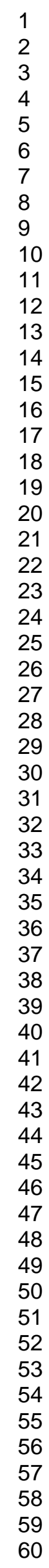

SCHOLARONE ${ }^{m}$

Manuscripts 列

25

26

27

28
29
30

30

31

33

34

35

36

37

39

40

41

42

44

45

46

47

48

50

51

52

53

54

55

57

58

59

60

http://mc.manuscriptcentral.com/tprs Email: ijpr@tandf.co.uk 
Front Page

\title{
Developing an Optimum Maintenance Policy by Life Cycle Cost Analysis - A Case Study
}

\author{
Khaled El-Akruti \\ School of Mechanical, Materials and Mechatronic Engineering \\ University of Wollongong \\ Wollongong, NSW 2522, Australia
}

Tel. +61 242215052

Email. khaled@uow.edu.au

Tieling Zhang*

School of Mechanical, Materials and Mechatronic Engineering University of Wollongong

Wollongong, NSW 2522, Australia

Tel. +61242214821

Email.tieling@uow.edu.au

Richard Dwight

School of Mechanical, Materials and Mechatronic Engineering University of Wollongong Wollongong, NSW 2522, Australia

Tel. +61242211318

Email.radwight@uow.edu.au

* The corresponding author is Tieling Zhang (Email. tieling@uow.edu.au) 


\title{
Developing an Optimum Maintenance Policy by Life Cycle Cost Analysis - A Case Study
}

\begin{abstract}
This paper focuses on developing maintenance policies for critical assets to improve the production performance based on life cycle cost (LCC) analysis. A general approach is adopted for conducting the LCC analysis.

The investigation is based on a case study to demonstrate how an optimum maintenance policy is determined. The relevant LCC structure in the case study is defined for the decision process which involves determination of the optimum life, repair limit and selection of materials, and trade-off between repair and replacement. The LCC analysis is based on statistical data modeling which facilitates decision making on the optimal replacement of an asset and its remaining life. Based on the optimization and remaining life criterion, the optimal maintenance policy can be made. The results obtained from this case study include selection of the best lining material for use, determination of the optimal time for refractory lining replacement, the hot repair sequence required for maintaining the optimum condition and the repair limit for doing cold repairs before replacement, for one type of electric arc furnaces (EAFs) used in the steel industry.
\end{abstract}

Keywords: Maintenance policies, asset management, life cycle cost, optimum replacement, remaining useful life

\section{Development of Maintenance Policies by Considering Life Cycle Cost Approach}

Many quantitative approaches and models have been developed to deal with the maintenance policies but they mostly focused on repair versus replacement of machinery and mechanical systems (Eginhard 1977, Jarddeine 1979, Zhang 2000, Lai 2001, Motta 2002). It is not until recently, when practical attempts have been made to deal with the relationship between maintenance strategies and the overall business objective of organizations (Tsang 2002, Pinjala and Pintelon 2006, Muchiri et. al. 2010, El-Akruti 2012). The same can be said about the development of quantitative models that use LCC to cover the impact of maintenance policies on the overall performance and value contribution to the organization (Khan 2001, Motta. and Colosimo 2002, Hartman 2004, Scarf et.al. 2007, Shahata and Zayed 2008, Lad 2012, Marais 2013).

Considering the relation between maintenance strategies and the overall business objective of organizations, it was proposed that knowledge of developing the LCC approach and models were essential for the formulation of optimum maintenance policies. In order to make some knowledge contribution in such direction, it was decided that a field investigation of an actual case study should be carried out for the dual purpose of developing the LCC approach as realistic as possible and for the application and evaluation of the quantitative optimization model through the use of past operational and cost records. 
LCC analysis plays an important role in developing maintenance policies (e.g. Lad and Kulkarni, 2012; Taylor, 2012; Tähkämö et al., 2012; Mahapatra, 2008; Garcia et al., 2008; Shahata and Zayed, 2008; Scarf et al., 2007; Schuman and Brent, 2005; Hartman, 2004; Goralczyk and Kulczycka, 2003). LCC is directly influenced by decisions and activities from system preliminary design to utilization stage including system analysis, evaluation of alternatives or trade-offs. LCC may be reflected by the costs committed to and/or being incurred during the asset life cycle (Blanchard and Fabryky, 2010, p. 585), because asset operational management including maintenance is carried out through the entire asset life (Charles and Alan, 2005; Luan, et al., 2007). El-Akruti (2012) argues that LCC analysis is essential in managing the overlaps among the interdisciplinary activities in assets' life cycle. Maintenance policies development is related to procurement, finance and accounting department which enable investment, funding and budgeting in asset development.

During utilization of assets, maintenance policies are determined upon certain types of maintenance. This process may involve decision makings on outsourcing, upgrading, expansion, support system development, redesign, replacement or retirements of assets. To make these decisions requires for conducting LCC analysis. For example, Ouertani et al. (2008) argue that maintenance is complex and so deserves additional attention. Thus, maintenance policies development needs to be built on LCC among many other organizational activities and through all life cycle stages. Pinjala et al. (2006) discuss the relationship between an organization's business objectives and some of the maintenance activities and Khan (2001) presents that system reliability is related to LCC. A strategic approach to making maintenance strategies and policies has been recognized especially in capital-intensive industries (Tsang, 2002; Pinjala et al., 2006; Muchiri et al., 2010).

Integration of LCC into decision making models requires defining requirements, performance targets, availability of input data, priorities and alternatives for solution, cost contributors and cause-effect relationship; and setting an appropriate cost breakdown structure (Blanchard and Fabrycky, 2010). In the policies development, LCC is a critical factor in decisions related to dealing with one or more issues as follows:

1) During the utilization of the asset, replacement cost must be considered as a function of the current system's behavior to establish the remaining costs of the asset life.

2) The decision logic on repair/replacement must lead to economically optimized repair frequency and replacement time interval.

3) Prediction and estimation of asset condition may require condition monitoring system with breadth and depth for visibility.

4) At design phase, the investment as well as system operation and support costs need to be estimated. It is usually difficult to estimate/predict accurately the future operation and support costs.

5) Trade-off decisions may involve capital vs. running costs; labor \& materials $v s$. reduced services and reduced safety. 
6) Decisions on alternatives need to be made based on the comparison criteria for asset management according to maintenance strategies, policies or methods and balancing the cost of a new item against the cost of maintaining efficiency of the old.

\section{The Significance of Using Life Cycle Cost Analysis}

The purpose of conducting a quantitative LCC analysis in developing maintenance policies is to cover the interrelationships between maintenance activities and other relevant life cycle or support activities of the organization in order to avoid sub optimization and achieve maximized economic benefits while maintaining the optimum system performance (Khan 2001, Schuman and Brent 2005, Muchiri et. al. 2010, El-Akruti 2012 Marais 2013). The quantitative LCC analysis methods can ensure a realistic selection of the maintenance policies together with associated activities, which maximizes the expected values if they are based on cost minimization and output maximization (Marais, 2013). There are many methods developed for carrying out a model-based LCC analysis using historical data such as using graphical tools (Barberá et. al., 2013) in maintenance decision making. Statistical methods or reliability techniques are also used for maintenance decisions and policy settings (e.g. Motta and Colosimo, 2002).

LCC models can help in developing criteria to improve the overall organizational benefits with the same cost spent or reduce the cost with the same performance maintained in terms of cost/benefit mixtures. For example, in order to find the optimal LCC, control of replacement and/or repair frequencies is needed while considering impacts by/on other activities in the organization. Maintenance control is meaningless unless there is a criterion to tell when the control is serving the overall benefit of the organization. Such criteria do not exist and it involves a search for it in the context of the demand for the asset. The effectiveness of maintenance must allow the asset's performance to meet the demand. It is therefore a twoway interaction. On one hand it is demand for equipment and on the other hand it is the equipment condition. In between, the replacement and/or repair actions must be well planned.

In maintenance control for optimization, there are two tasks to be completed: One is the determination of how to measure the performance for the overall benefit of the organization and the other is identification of the decision criteria with control variables which are manipulated by the replacement function in order to set up a policy. If the performance measures can be laid down clearly and can be met, the performance can be judged in terms of cost for providing the required service to achieve the overall organizational benefit.

Even if availability and performance are specified, one can question the true financial effects of the production at each service level. Thus what are the financial effects of no production time due to repair/replacement and poor quality? What are the financial effects of delaying production resulting from not having equipment available? This gives rise to the need to combine both functions of minimizing LCC to achieve various service levels and maximizing the overall economic benefits for the organization. Finally it needs to remember that the way in which an asset is used in production programs will inevitably influence the 
condition of the equipment. Sometimes, the decision is to be made on delaying production as against to using asset with risky condition where deterioration may be rapidly and catastrophically accelerated.

In developing maintenance policies, different decisions are to be made at different hierarchical levels including, e.g. inspection and replacement of component, repair or overhaul of equipment, replacement, etc. The effect of these decisions cannot be separated. Their combined effects on operation and maintenance have to be assessed when dealing with policies development. For example, an optimum overhaul frequency for replacement of some components depends on the frequency of replacement of other associated components. A component may or may not be replaced at times of major overhauls and at time of breakdown. LCC is considered for replacement decision which does not have to be in the strict sense of the word, but perhaps maintenance decisions on repair and overhaul may be taken as synonymous with replacement provided that it is reasonable to assume that maintenance actions return the equipment to as new condition. Therefore it is not a 'one-off' decision, but a series of decisions. Thus the decision structure is complicated and not all decisions can be dealt with by considering LCC at the same time.

In order to avoid sub optimization and determine an optimum maintenance policy that serves the overall benefit of the organization, a general approach to developing LCC analysis as given by Blanchard and Fabrycky (2010) has been adopted here by modification as follows:

1) Define system requirements and technical performance measures (TPMs).

2) Specify the system lifecycle and identify activities by phase.

3) Develop a cost breakdown structure.

4) Identify input data requirements.

5) Establish costs for each category in cost breakdown structure (CBS).

6) Select a cost model for analysis and evaluation.

7) Develop a cost profile and summary.

8) Identify high-cost contributors and cause-effect relationships.

9) Develop decision making models and set up decision criteria.

10) Conduct a sensitivity analysis.

11) Identify priorities for problem resolution.

12) Identify additional alternatives and select a preferred approach.

13) Evaluate feasible alternatives and select a preferred approach.

The similar process can be found from standards such as AS/NZS4536:1999 (1999) and ISO 15663-3:2001 (2001). By following the adopted approach, an optimum maintenance policy can be determined properly by minimizing LCC while achieving various service targets and maximizing the economic benefits. This will be demonstrated by a case study as shown in Section 3. 


\section{Case Study - EAF's Lining Repair and Replacement Policies}

This case study focuses on providing the refractory maintenance department and operation department in a particular steel making company with a maintenance policy that guaranties and outlines the economical decision bases for replacement and repair practice. It covers the role of LCC analysis in developing an optimum maintenance policy for an electric arc furnace $(\mathrm{EAF})$ in terms of establishing decision making support quantitative model utilizing LCC data to help asset management:

1. Select the appropriate refectory lining material suppliers based on performance and economical lining life, and

2. Determine the optimal lining replacement cycle and repair intervals and/or limits

\subsection{EAF's lining as a critical asset component}

EAFs are the most critical assets to maintain the production process in a steel making plant. The main activities applied onto the EAFs are replacement and repair of linings in its main components, which impact on the process availability. Fig. 1 shows a schematic illustration of a 90 ton/heat EAF considered in this case study which is composed of three main components of roof, sidewall and hearth (Gadpayle and Baxi 2014). The roof can be replaced by new standby one with relatively no impact or loss of production. The repair and replacement of the sidewall and hearth are done simultaneously and have direct effect on EAF productivity and refractory lining management and therefore they are considered together in the decision support model development.

The lining within each component is divided into permanent lining and working lining. Working lining is the layer in contact with molten metal and permanent lining is the layer between working lining and the metal structure of the EAF as shown in Fig. 1. The most important element of EAFs with respect to its operation is its working lining. It is the sidewall working lining's life and its replacement that determines the campaign time and the furnace availability. However, both sidewall and hearth are interrelated in terms of the lining layers which are in direct contact with the molten metal. The maintenance policy for working lining, i.e. replacement and/or repair to a large extent impacts on the availability and productivity of the process, resulting in a great effect on the unit cost of liquid steel produced.

(Figure 1 is a bout here)

Repair of simple erosion in localized spots of the working lining can be done between heats during operation using gunning and fettling on sidewall and/or ramming for the hearth while the EAF is hot; this is called hot repair. Repair can also be done after stopping and cooling the EAF by replacing ramming or bricks of damaged areas due to excessive localized erosion; this is called cold repair. The repair/replacement action to be taken on EAFs involves decision making in cyclic manner as illustrated by a tree diagram as shown in Fig. 2. It is clear from the tree diagram that at any stage (at the end of any heat) of production, there is a 
decision point where one out of five alternatives is selected. Although due to safety inspection is required after tapping each heat, decisions that are based on personal judgment will not optimize the practice in the absence of a decision support model to determine optimal criteria.

(Figure 2 is a bout here)

The service life of the working lining is dependent on operation conditions and repair practice. The amount and quality of material used and the time required to do hot repair are the main factors in considering hot repair cost. Cold repair is usually resorted to when deterioration or damage cannot be handled by hot repair. It is time consuming because it requires cooling the EAF down which results in a great loss of EAF's availability. The time required for cooling EAF and the time required for repairing are the main factors in considering cold repair cost. Hence it would be more appealing to enhance the quality of lining to withstand the working condition for longer replacement intervals.

Two types of lining replacement exist from the procedure shown in Fig. 2. One is replacement of permanent lining and the other is replacement of working lining. Permanent lining replacement takes place after a fixed time period, denoted as, tp. tp is adopted as 5000 $\sim 6000$ heats in the current policv in the case studv as per designer's recommendation. Rer Figure 2 Description of the decisions involved in replacement and repair procedure ict on operation. The time period between two working lining replacement actions is denoted as tw. In practice, it may take 2 to 3 or more years before tp reaches 5000 heats, for example, but working lining replacement may take place from 3 to 9 times in one year depending on demand for production, operation conditions and raw material quality. Therefore, tw is more relevant than tp for determining maintenance optimization criteria and the effect of tp on EAF's refractory cost is relatively small.

According to information obtained from refractory lining suppliers and benchmarking done by the case study company, the actual service life and the mechanism of replacement and repair of EAF working lining is different from one steel plant to another depending on environment, raw material and operational conditions. The range of variation of actual tw from one steel plant to another is in the vicinity of 140 to 500 heats.

Comparatively, tp is longer than tw. Permanent lining replacement is at a fixed time period and based on designer recommendation. As a result, it has relatively little or no effect on the economics of EAF lining maintenance and is considered irrelevant to optimal maintenance policy development for EAF lining. Working lining replacement is the most relevant aspect because it is directly related to the overall cost of replacement and repair, and costs and/or losses due to stoppage of the EAF for repair. Consequently an assessment of working lining replacement cost in terms of lining material and the costs and/or losses due to stoppage of the EAF for replacement is required for constructing the LCC model. The costs or losses that 
result from the stoppage of the EAF due to repair or replacement are included in the cost breakdown structure as a cost element called stoppage cost.

The maintenance policies concerned in this case study include hot repair, cold repair and replacement of working lining. Cold repair is considered as a partial replacement where the EAF has to be cooled down. Hence it can be concluded that hot and cold repair are as relevant aspects as working lining replacement because they have direct impact on LCC which involves the overall cost of replacement and repair, and stoppage cost. Consequently the hot and cold repair costs in terms of materials used and stoppages should be taken into account in the LCC structure. Furthermore the two types of repair costs need to be considered separately as hot repair is applied as required and hence does not require application decision whereas cold repair requires an application limit as a decision variable in the model and which has to be estimated according to the decision criteria.

In summary, there is a need to develop cost-effective criteria for determining the optimal maintenance policy based on LCC and each plant has to develop its own convenient replacement and/or repair policy.

\subsection{Decision models and LCC criteria}

The aim of this case study is to demonstrate and establish the modeling procedure using LCC to set up a maintenance policy that economically control the replacement and repair practice of refractory working lining in EAFs. The main decisions involved in modeling an economical maintenance policy are:

1) Minimizing the LCC per unit production in treating of replacement and repair, so as to obtain the optimum life of EAF's working lining (economical life);

2) Determining the cold repair economical limit in terms of cost and life;

As a result, it involves answering the following questions in this case study:

1) Which lining type (supplier) is better?

2) When will lining be replaced in a cyclical manner?

3) At what sequence is hot repair required relative to lining life?

4) Is cold repair used before replacement and how to determine the repair limit for use?

The bases for making these decisions are lining life in heats and LCC. It is intended to set up a maintenance policy to meet the economical targets. That is to reduce LCC while increasing productivity and maintaining the required quality. As a result, those economical targets should be achieved through obtaining an optimum replacement model and a repair limit model.

\subsection{Decision models development and integration}

\subsubsection{Essential assumptions}

The relevant assumptions used in this case study are shown below:

a. Since working lining replacement occurs 3 to 9 times in a year, the unit price of material is assumed to be constant over the replacement period and the unit price may 
be updated yearly. Similarly, no cash discounting shall be resorted to.

b. After new working lining is installed, the lining cost is assumed to be equal to the new working lining cost at zero life and equal to zero at the optimum life, meaning, zero salvage value of lining at replacement so that the depreciation cost would be the full replacement cost.

c. Operating cost will not be considered in the cost model structure and assuming that it does not change with the age of the lining.

d. Replacement, hot or cold repair duration is assumed as a time period of stoppage of EAF; "no operation" status.

e. All "no operation" time periods incurred for hot or cold repair or replacement are counted in calculation of stoppage cost.

f. The cost of second hand bricks or materials used in cold repair is assumed to be zero.

g. Cold repair limit is assumed to be evaluated on the basis of the working lining value (remaining age value) at any stage of production.

h. The remaining age value is evaluated by linear regression using the statistical cycle length data between two replacement actions.

\subsubsection{Models involved and data for modeling}

The required models involve quantitative replacement modeling and repair limit prediction modeling. Models are developed on the basis of EAF past data that includes the deterioration rate and the constant random failure rate.

The optimum replacement model and repair limit model can be obtained by statistical analysis and modeling of the EAF past data for determining the optimum lining life. The data obtained for analysis includes cost, operation and refractory lining material data of three different suppliers' lining material types for the latest 5 years of operation. Data on working lining replacement and repair for each supplier material type was collected for each heat and then the data was grouped in a time period of every 10 heats for analysis. Then, the entire cost elements that make up the LCC are determined; which are the costs of operation, repair, stoppage, depreciation, etc. The average LCC per period can be determined. That is the sum of the depreciation cost, and operation and repair costs. The depreciation cost per period keeps decreasing while the operation and repair costs are increasing in usage time of EAF lining. Therefore, the average LCC per period will decrease from commissioning to a minimum level with increase of usage time due to decreasing of average depreciation cost per period. After that, the average LCC per period will start to go up when the increase in average operation and repair costs per period exceeds the decrease in average depreciation cost per period. This minimum level of average LCC per period represents the criterion for determining the optimum replacement point and the time span from the start point of commission of a new working lining to this optimum replacement point represents the “optimum replacement cycle length". 
The repair limit is related to determining the remaining age value of the lining. Since the optimum lining life is maintained statistically, the remaining age at any service stage can be evaluated by linear approximation as given in Equation (1) with assumption that the final age value (FAV) is equal to zero.

$$
\mathbf{L v}=\frac{\mathrm{Cw} \times(\mathbf{O H}-\mathbf{H i})}{\mathbf{O H}}
$$

where, $\mathbf{L v}$ is the remaining age value to be determined, $\mathbf{O H}$ is the optimum lining life which is the statistical average life, $\mathbf{H i}$ is the service life of the lining, $\mathbf{H e}$ is the expected remaining life of the lining $(\mathbf{H e}=\mathbf{O H}-\mathbf{H i}), \mathbf{C w}$ represents the initial age value which is equal to the working lining cost.

\subsubsection{Integrating models and decision criteria in practice}

The criteria may be divided into procurement and operational decision criteria. The procurement decision criterion is related to the alternatives in terms of types of lining material (suppliers), and the decision criterion variable is the minimum LCC per unit production, denoted for this case as average LCC per heat. The alternative with minimum average LCC per heat is to be selected.

The operational decision criteria are related to the alternative repair routes as shown in Fig. 3 , which represent the integration of models within the overall operational procedure with all decision making events indicated.

(Figure 3 is a bout here)

\subsubsection{Cost structure breakdown and cost elements evaluation bases for modeling}

As decision criteria are based on cost data, various types of costs involved in lining repair and replacement must be outlined. These costs are structurally related as shown in Fig. 4. It should be noticed that some are not used because they either have no impact on the replacement and repair practice or do not change with respect to time or replacement and repair events. The main cost elements that have impact on decision regarding replacement or repair are working lining cost, cold repair and hot repair cost and stoppage cost as shown in Fig. 4.

(Figure 4 is a bout here)

\subsubsection{Bases for material cost and stoppage cost evaluation}

a. Material cost

The material cost is made up of the cost of various components which may be brick or mixes and/or binding material for the lining or the various used components of the repair material. The total material cost $(\mathrm{Cm})$ is calculated by

$$
\mathrm{Cm}=\sum_{\mathrm{i}=1}^{\mathrm{n}}\left(\mathrm{Uw}_{(\mathrm{i})} \times \mathrm{Uc}_{(\mathrm{i})}\right)
$$


where, $\mathrm{Uw}_{(\mathrm{i})}$ is the total weight of material component $i$ and $\mathrm{Uc}_{(\mathrm{i})}$ is the unit cost of the component $i$ (cost per unit weight).

b. Stoppage cost

In a general sense of production, stoppage time is time loss that could have been utilized for production. The stoppage cost is calculated by considering the following two aspects: One is the loss of operation time or "no operation time" resulting in an ongoing payment of the fixed cost and the second is "loss of products" that could have been produced in the stoppage time and then sold and therefore a possible result of lost benefit. Therefore, the stoppage cost, $\mathrm{Cs}$, is defined as $\mathrm{Cs}=\mathrm{NOC}+\mathrm{LBNP}$, where NOC represents the "no operation cost" which is mainly due to contribution of the ongoing fixed cost and LBNP represents the "lost benefit due to no production" because of "loss of products".

In general, the production benefit during one lining life is calculated by the following:

$$
\mathrm{P}_{\text {pro }} \times \mathrm{A}_{D} \times L_{H} \times p_{s}-\mathrm{T}_{\text {repair/replace }} \times \mathrm{P}_{\text {pro }} \times p_{s}-\mathrm{C}_{\text {repair/replace }}-\text { Others }
$$

where $\mathrm{P}_{p r o}$ is average productivity (tons/heat), $\mathrm{A}_{D}$ is average equipment availability in normal production, $L_{H}$ is lining life evaluated in number of heats, $p_{s}$ is sale price of the product in unit of dollars/ton, $\mathrm{T}_{\text {repair/replace }}$ is the time used for repair and replacement in one lining life $\left(\mathrm{T}_{\text {repair/replace }}\right.$ is converted into number of heats in the calculation). In this equation, $\mathrm{T}_{\text {repair/replace }}$ $\times \mathrm{P}_{\text {pro }} \times p_{s}$ is equivalent to a cost and named as lost production cost; $\mathrm{C}_{\text {repair/replace }}$ includes lining material cost utilized and cost paid for man-hours used for repair and replacement actions; and others are those costs associated with necessary facilities and production support.

For the EAF refractory lining case, the replacement of working lining takes place 3 to 9 times during one year and therefore replacement and repair decisions are more related to cost figures during the year for which the production program is determined.

The value of the ongoing fixed unit cost $(\mathrm{NOCu})$ is estimated based on the following:

$$
\mathrm{NOCu}=\mathrm{C}_{\text {Dep-u }}+\mathrm{C}_{\text {Ins-u }}+\mathrm{C}_{\text {Adm-u }}+\mathrm{C}_{\text {Lab-u }}
$$

where, $\mathrm{C}_{\text {Dep-u }}, \mathrm{C}_{\text {Ins-u }}, \mathrm{C}_{\text {Adm-u }}$ and $\mathrm{C}_{\text {Lab-u }}$ are depreciation cost, insurance cost, administrative cost and labor cost, respectively. Each of them represents unit cost where the unit time refers to one hour, day or month; or each of them refers to the cost incurred per one heat, respectively.

The "lost benefit due to no production", LBNP, is obtained by

$$
\mathrm{LBNP}=\mathrm{T}_{\text {repair/replace }} \times \mathrm{P}_{\text {pro }} \times p_{s}
$$

where the meaning of each term is the same as in Eq. (3).

As a result, the stoppage cost is evaluated by

$$
\mathrm{Cs}=\mathrm{T}_{\text {repair/replace }} \times\left(\mathrm{NOCu}+\mathrm{P}_{\text {pro }} \times p_{s}\right) .
$$

\subsubsection{Model cost elements evaluation}

Working lining replacement cost $(\mathrm{Cw})$ is broken down into five basic elements, and each of Cold repair cost $(\mathrm{Cc})$ or Hot repair cost $(\mathrm{Ch})$ also includes five basic cost elements as shown in Fig. 4. The material cost evaluation for working lining replacement cost and Cold repair cost is shown in Table 1 . Hot repair, however, is defined in terms of gunning and 
fettling and hence Hot repair material cost is composed of gunning cost and fettling cost (including cost of material used), i.e. $\mathrm{Chm}=\mathrm{Cf}+\mathrm{Cg}$ where $\mathrm{Chm}$ is Hot repair material cost, and $\mathrm{Cf}$ and $\mathrm{Cg}$ represent the cost of gunning and the cost of fettling, respectively.

\subsection{Model formulation}

\subsubsection{The optimum replacement cycle model formulation}

The formulation of replacement is tabulated as shown in Table 1. For simplification, the formulation in Table 1 is only shown in terms of the main variables that give their logical relations with the operation decision criteria. Here, the operation decision criterion is to find the optimum cycle length, $\mathrm{OH}_{(\mathrm{t})}$.

$\mathrm{OH}_{(\mathrm{t})}$ is evaluated on the base of the minimum average LCC per heat (Cta) determined within the replacement cycle and based on the collected statistical data in each cycle. In utilizing the developed replacement cycle model, after each heat production the operator needs to check whether the optimum replacement cycle length, $\mathrm{OH}_{(\mathrm{t})}$ determined by the model is reached in order to avoid doing any further repair beyond that optimum replacement cycle length point and replace the working lining. For the period at which replacement is decided to be undertaken, the hot repair cost per period (Chp) is determined as the maximum hot repair cost per period and denoted as Chpmax.

Using statistical analysis, the replacement cycles for each supplier's material type are assessed. The procedure for obtaining the optimum replacement cycle, $\mathrm{OH}_{(\mathrm{t})}$ for each supplier's material type is shown by the flow chart in Fig. 5. In the flow chart, Cha, Cra, Cca, Cwa and Cta are average value per heat of hot repair cost, replacement cost, cold repair cost, work lining cost and LCC, respectively; $\mathrm{Cr}$ is repair cost; $\mathrm{Gp}$ is number of gunning per period and Chs represents hot repair service cost. The rest terms shown in Fig. 5 have been defined in Table 1, 2 and 3.

The average values of model variables and decision criteria are assessed based on average values per material type as shown by the chart in Fig. 6. For each supplier's material type, a representative average cycle (jav) is determined, parameters are plotted and decision criteria are determined based on the following:

- Determining and adopting the optimum life per material type as $\mathrm{OH}_{(\mathrm{jav})}$ by comparing the LCC per period (i+1) to the previous period (i) for determining the optimum cycle length when $\mathrm{Cta}_{(\mathrm{i}+1)} \geq \mathrm{Cta}_{(\mathrm{i})}$ as illustrated in Table 2 .

- Adopting the optimum average LCC per heat as the minimum criterion, $\mathrm{Ctamin}_{(\mathrm{jav}, \mathrm{t})}$;

- Identifying and adopting the maximum hot repair per period as $\mathrm{Chpmax}_{(\mathrm{jav}, \mathrm{t})}$; and

- Identifying and adopting the maximum gunning per period as $\operatorname{Gpmax}_{(\mathrm{jav}, \mathrm{t})}$.

From Fig. 5, all lining material types are compared and the best material type with the minimum average LCC per heat is selected.

A spreadsheet programing is developed of the formulated model which can be used to enter data directly from the start of utilization of the working lining while calculating the optimum life cycle length $\mathrm{OH}$ after each heat production. 
(Table 1 is a bout here)

(Figure 5 is a bout here)

\subsubsection{The repair limit model formulation}

The repair limit model is developed to help decide whether a cold repair is worthwhile based on the repair limit criterion. The procedure is dependent on the information from the optimum replacement model. The input variables for the model are composed of the output variables of the optimum replacement cycle model and the service life variable. The procedure involved in the repair limit model is based on defining the remaining age value and setting the cold repair limit in terms of remaining age value and service life. The main variables involved in the repair limit model are summarized with their logical relation to operation decisions as given in Table 2 and Table 3. Again, the repair limit can be checked after each heat production if the spreadsheet program is used.

(Table 2 is a bout here)

(Table 3 is a bout here)

\subsection{Model results analysis and implication}

\subsubsection{Model results}

By entering the required historical data, e.g., operation and maintenance data of each of the three lining types from the three different suppliers for a period of analysis of 5 years into the developed model, solutions are obtained for every working lining replacement of all suppliers' lining material types for the 5 years period. An average replacement cycle is obtained from the solutions for each supplier's lining material type and denoted as the average value for each supplier's lining material. These average solutions for the three different suppliers' lining materials provided basis for comparison and a view on the economics of repair and replacement for decision making based on the LCC per heat, repair cost per heat and the gunning consumption per period. They also provided a view on the impact of using cold repair and/or the change in the hot repair frequency and amount used in terms of gunning and fettling on the optimum replacement cycle length. For the purpose of this paper, it is not possible to present all solutions but as a sample solution, Figs. 6 (a) and 6 (b) show the results from analysis that determined the optimum replacement cycle length and frequency of hot repairs for one supplier lining material. Fig. 6 (a) shows optimization with cold repair done on the lining while Fig. 6 (b) shows the optimization without using cold repair. In the two figures, Cha, Cra, Cca, Cwa and Cta are average values per heat of hot repair cost, replacement cost, cold repair cost, work lining cost and LCC, respectively. 
(Figure 6 is a bout here)

\subsubsection{Model analysis and implication}

The sensitivity analysis provided by the model as shown in Table 4, is based on generated values from historical data considering the main decision variables and their impacts on the overall benefit of the organization.

(Table 4 is a bout here)

From this sensitivity analysis in Table 4, it can be clearly seen that the most important parameter is related to the decision of purchasing the most economical type of material to use. As shown in Table 4, the model managed to rank the three types of refractory materials for purchasing purposes in their order of viability as B, A and C. It also managed to provide the tool for the operational control of the replacement cycle in the presence and the absence of a cold repair requirement. The illustrative 12 life cycle samples assessments indicate the losses incurred as a result of operating with the refractory lining beyond its optimum replacement point in each case. Sample 8 is proven to be the best which is using material type $\mathrm{B}$, with no cold repair used and with an average hot repair per interval that costs $\$ 2226.25$. The use of hot repair per interval seems to be higher when using material type A, e.g. in sample 4 which is the best for material type A, the hot repair cost per interval is $\$ 2358.75$. Increasing the hot repair for material type A to $\$ 2762.70$ helped extending the optimum life of the lining to 370 heats but increased the optimum LCC per ton of liquid steel produced. In case of material type $C$, increasing the hot repair per interval did not help to increase the life of the lining or reduce the optimum LCC per ton of liquid steel produced.

The hot repair interval for repairing the defects can be modeled by a 3-parameter Weibull distribution given by

$$
F(t)=1-\exp \left[1-\left(1+\lambda t^{\beta}\right)^{\alpha}\right]
$$

with $\alpha, \beta$ of shape parameters and $\lambda$ of scale parameter where $F(t)$ is cumulative distribution function of the hot repair interval, $t$ (Zhang et al., 2013). In this case study, we got the model parameter estimates with $\alpha=3.259, \beta=1.387$ and $\lambda=0.00039$. The model and other 2- or 3parameter Weibull models could be used further to develop the relation between deterioration rate and repair sequence.

The generated values for the application of the decision variables are summarized in Table 5 for each supplier's material type.

(Table 5 is a bout here) 
The implication of using the model outputs in decision making is to determine the optimum policy results in cost reduction for the company. The evidence can be extracted from Table 5 as follows:

- An annual saving of $10 \%$ to $15 \%$ in the refractory cost with comparing Supplier-A to Supplier-C (about $\$ 1,700,000$ ) is expected to achieve when managerial decision is made for material type selection based on the model output.

- An annual saving of $2 \%$ to $6 \%$ in refractory cost is expected to achieve when operational decisions are based on the model output.

\section{Conclusion, Recommendation and Further Research}

LCC is a critical and essential measure used in decision making for maintenance management. In this paper, an approach is developed for fitting the LCC analysis procedure into maintenance policies development based on a case study. This approach to the maintenance policies development based on LCC analysis is believed to be a useful guideline which is able to be adapted to other systems in industry. The provided case study gives details of the application of the approach.

Through the case study, it is demonstrated that LCC analysis is utilized to develop a replacement model in which the procedure for analysis for the determination of the optimum policy based on the LCC decision criteria are described. The decision criteria are used as bases for decision making regarding the actions of replacement, repair and selection of the material suppliers. They can be used for decision making within the direct and support functions of the company. Therefore, the developed LCC-based model can serve as a decision support system as illustrated in the case study.

The application of the results is carried out in terms of the values determined by the model analysis for the decision parameters as given in Table 5. A decision process has been developed for using these values together with relations to the management system of the company for decision making. The decision making also allows for taking into account the advantage of arranging replacement or repair of any furnace in utilization when there is no full demand required.

The developed model provides an attractive proposal for top management to adopt. The spreadsheet program application requires a very simple procedure that would not impose any change in the actual operation or managerial practice and can determine the decision criteria for replacement or repair directly from the actual data entered for the particular EAF lining in use.

The recommendation for application includes:

- Operational recommendation

1) Replace the lining at the optimum life or as close to it as possible.

2) Observe gunning amount for every sequence of 10 heats and use it as an indication for assessing cold repair economical application limit. 
3) Cold repair should not be applied if its cost exceeds the limit. If applied, the cost per heat at replacement will be higher than what it is at cold repair application.

4) Even though hot repair should be applied as required, it is better to do it more frequently with small amount than less frequently with big amount.

5) Start to do hot repair approximately after the 20th heat as required.

6) For lining life less than 100 heats, hot repairs should be applied with a frequency from once per every 5 to 4 heats.

7) For lining life beyond 100 heats, hot repair frequency should not be less than once per every 3 heats and it would be increased as required depending on operation condition where it may be done at every heat.

- Managerial recommendation

1) When purchasing lining material, the decision on supplier selection should be based on the criterion of minimum LCC per unit production (per heat or per ton). The criterion relates price to performance for determining the most economical supplier.

2) The model should be updated in case of any future development, changing condition or new suppliers included.

Based on the approach presented and its demonstration through a case study, it is found that the research could be extended further to a few other research areas. The research topics may include:

- Correlation analysis between LCC and operation and/or maintenance parameters,

- The effect of operation parameters on maintenance policy selection and

- Mathematical modeling of failure rate or probability analysis of the deterioration rate of EAF's refractory lining.

\section{References}

AS/NZS 4536:1999, 1999. Australian/New Zealand Standard: Life cycle costing - An application guide.

Barberá L., Crespo A. and Viveros P., 2013. A case study of GAMM (graphical analysis for maintenance management) in the mining industry. Reliability Engineering and System Safety, 121, 113-120.

Blanchard B.S., Fabrycky W.J., 2010. Systems engineering and analysis: International Edition (5e). Englewood Cliffs, N.J. :, Prentice Hall, USA.

Charles A.S. and Alan C.B., 2005. Asset life cycle management: towards improving physical asset performance in the process industry. International Journal of Operations and Production Management, 25, 566-579.

El-Akruti K., 2012. The Strategic Role of Engineering Asset Management in Capital Intensive Organisations. Faculty of Engineering, University of Wollongong. Doctorate of Philosophy: 247, Australia.

Eginhard J.M., 1977. An optimal Decision Rule for Repair vs. Replacement. IEEE Transactions on Reliability, R-26(3), 179-181. 
Gadpayle S.P., Baxi R.N., 2014. Electric Melting Furnace - A Review. International Journal of Emerging Science and Engineering, 2(5), 80-83.

Garcia F.P., Lewis R.W., Tobias A.M. and Roberts C., 2008. Life cycle costs for railway condition monitoring. Transportation Research, Part E, ISSN 1366-5545, 44(6), 1175-1187.

Goralczyk M. and Kulczycka J., 2003. LCC application in the Polish mining industry. Management of Environmental Quality: An International Journal, 16(2), 119-129.

Hartman J.C., 2004. Multiple asset replacement analysis under variable utilization and stochastic demand. European Journal of Operational Research, 159, 145-165.

ISO 15663-3:2001, 2001. Petroleum and natural gas industries - Life-cycle costing - Part 3: Implementation guidelines.

Jardaine A.K.S., 1970. Operation Research in Maintenance. Manchester Univ. Press, Bannes and Noble, Inc. N.Y.

Khan F., 2001. Equipment reliability: a life-cycle approach. Engineering Management Journal, 11(3), 127-135.

Lai K.K., Leung K.N.F., Tao B. and Wang S.Y., 2001. A sequential method for preventive maintenance and replacement of a repairable single-unit system. J Opl Res Soc 52, 12761283.

Lad B.K. and Kulkarni M.S., 2012. Optimal maintenance schedule decisions for machine tools considering the user's cost structure. International Journal of Production Research, 50(20), 5859-5871.

Luan W, Siew C.K., Iosfin H., 2007. Life cycle analysis methodology for distribution feeder reclosers, Vancouver, BC, Canada, Institute of Electrical and Electronics Engineers Inc.

Mahapatra D., 2008. Life cycle costs and electricity market equilibrium: A policy assessment for India. 5th International Conference on European Electricity Market, 28-30 May, pp.1-6.

Marais K.B., 2013. Value maximizing maintenance policies under general repair. Reliability Engineering and System Safety, 119, 76-87.

Motta S.B. and Colosimo E.A., 2002. Determination of preventive maintenance periodicities of standby devices. Reliability Engineering and System safety,76, 149-154.

Muchiri P.N., Pintelon L., Martin H., De Meyer A.M., 2010. Empirical analysis of maintenance performance measurement in Belgian industries. International Journal of Production Research, 48(20), 5905-5924.

Ouertani M.Z., Parlikad A.K. and McFarlane D., 2008. Asset information management: Research challenges. Marrakech, Morocco, Inst. of Elec. and Elec. Eng. Computer Society.

Pinjala S.K., Pintelon L., Vereecke A., 2006. An empirical investigation on the relationship between business and maintenance strategies. International Journal of Production Economics, 104(1), 214-229.

Scarf P., Dwight R., McCusker A. and Chan A., 2007. Asset replacement for an urban railway using a modified two-cycle replacement model. Journal of the Operational Research Society, 58(9), 1123-1137.

Shahata K. and Zayed T., 2008. Simulation as a tool for life cycle cost analysis. Simulation Conference, WSC 2008. pp.2497-2503.

Schuman C.A. and Brent A.C., 2005. Asset life cycle management: towards improving physical asset performance in the process industry. International Journal of Operations \& Production Management, 25(6), 566-579. 
Taylor J., 2012. Asset Life Cycle Management: Case Studies on Asset Life Cycle Cost Modelling. Asset Management Council @ http://www.amcouncil.com.au/asset-management-body-ofknowledge/asset-management-council-presentations.html.

Tähkämö L., Ylinen A., Puolakka M. and Halonen L., 2012. Life cycle cost analysis of three renewed street lighting installations in Finland. The International Journal of Life Cycle Assessment, $17(2), 154-164$.

Tsang A.H.C., 2002. Strategic dimensions of maintenance management. Journal of Quality in Maintenance Engineering, 8(1), 7-39.

Zhang T.L., Dwight R., El-Akruti K., 2013. On a Weibull related distribution model with decreasing, increasing and upside-down bathtub-shaped failure rate. 2013 Proceedings of Annual Reliability and Maintainability Symposium, Jan. $28 \sim 31$, 2013, Orlando, Florida, USA.

Zhang Z.G. and Love C.E., 2000. A discrete semi markov decision model to determine the optimal repair/replacement policy under general repair. Eur J Opns Res 125, 398-409.

List of Figure \& Table Captions

Figure 1 A schematic cross-section of an EAF

Figure 2 Description of the decisions involved in replacement and repair procedure

Figure 3 Operational decision criteria and procedure

Figure 4 Cost structure breakdown in modelling

Figure 5 Optimum replacement cycle model

Figure 6 Determining the optimum number of replacement w/o using cold repair

Table 1 Formulation of the optimum replacement model

Table 2 Identifying variables and defining the repair limit

Table 3 Setting the decision criteria

Table 4 Sensitivity analysis provided by the model to show advantages and limitations for decisions

Table 5 Output values of the model for decision criteria and optimum status 
Figure 1 A schematic cross-section of an EAF $241 \times 97 \mathrm{~mm}$ (96 x 96 DPI) 


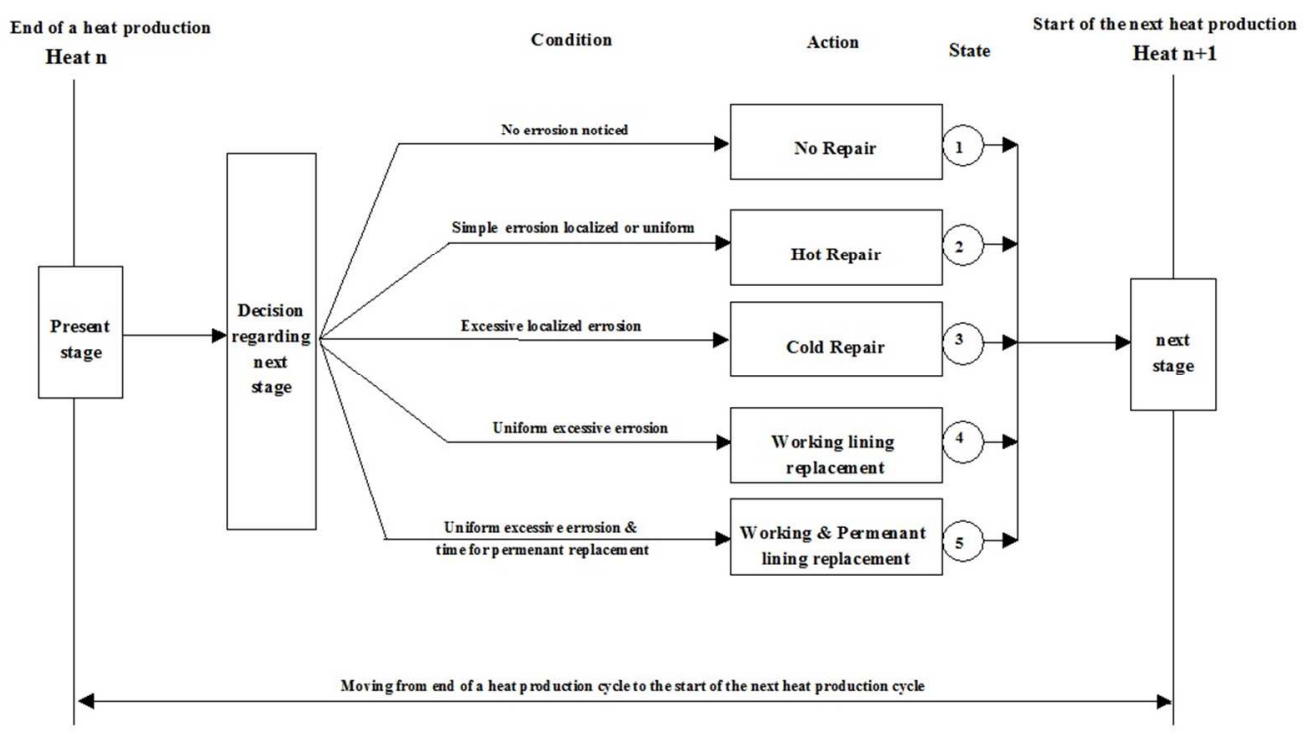

Figure 2 Description of the decisions involved in replacement and repair procedure $283 \times 157 \mathrm{~mm}(96 \times 96 \mathrm{DPI})$ 


1
2
3
4
5
6
7
8
9
10
11
12
13
14
15
16
17
18
19
20
21
22
23
24
25
26
27
28
29
30
31
32
33
34
35
36
37
38
39
40
41
42
43
44
45
46
47
48
49
50
51
52
53
54
55
56
57
59
60

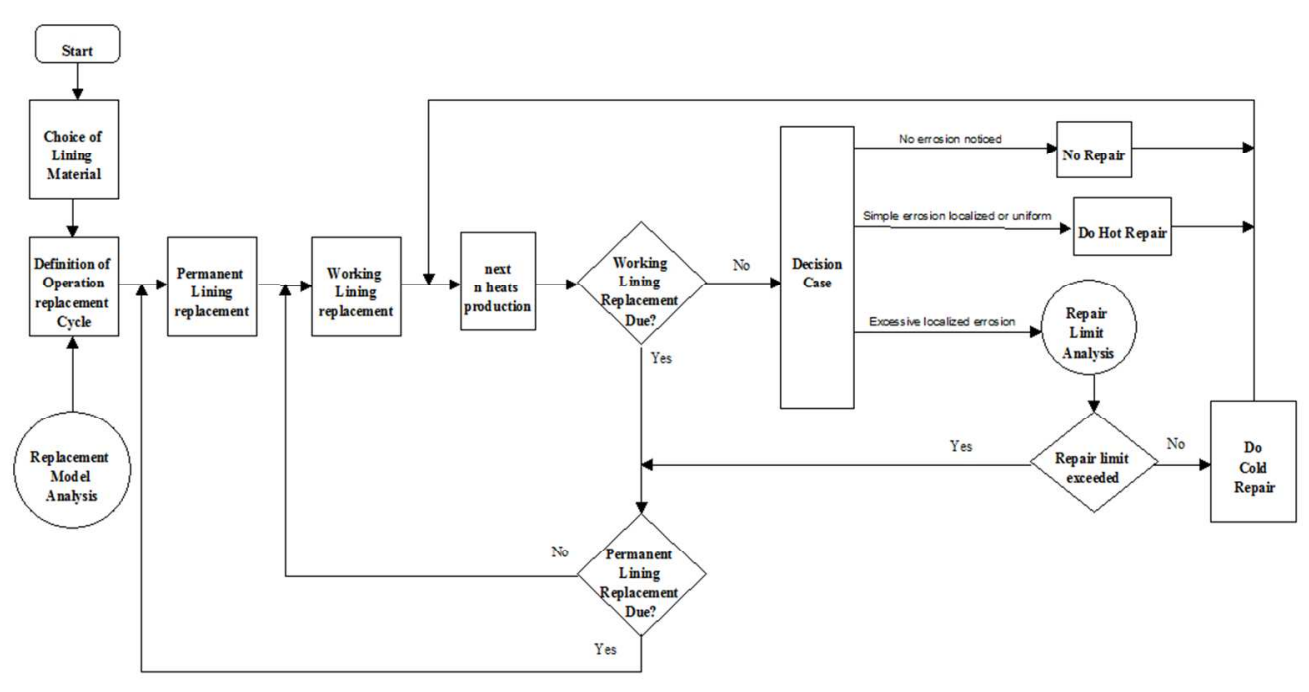

Figure 3 Operational decision criteria and procedure $286 \times 146 \mathrm{~mm}$ ( $96 \times 96 \mathrm{DPI})$ 


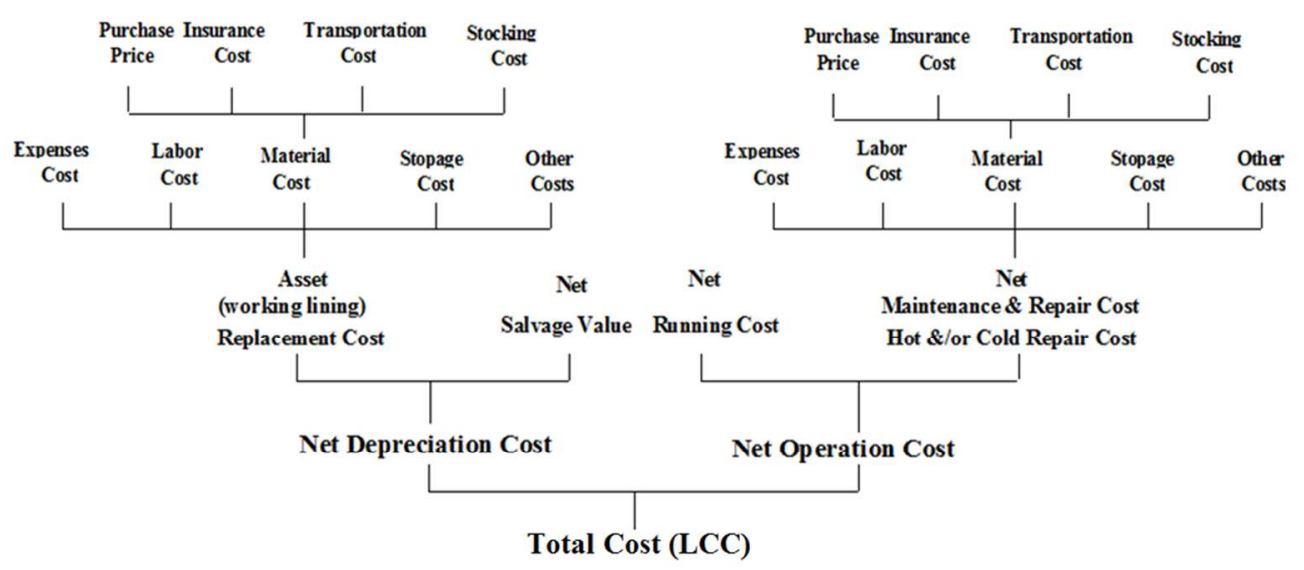

Figure 4 Cost structure breakdown in modelling $275 \times 120 \mathrm{~mm}(96 \times 96 \mathrm{DPI})$ 


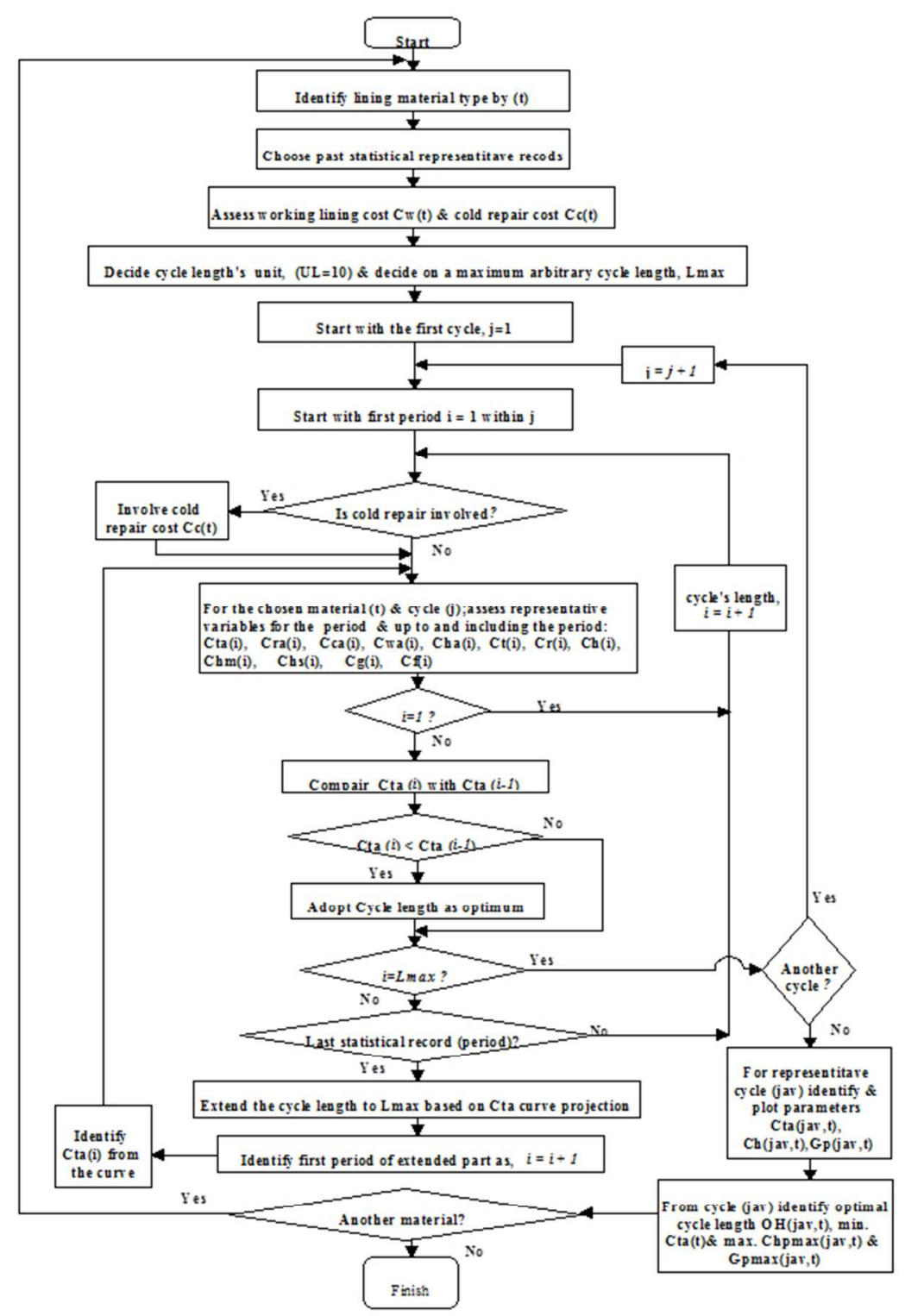

Figure 5 Optimum replacement cycle model $158 \times 237 \mathrm{~mm}(96 \times 96 \mathrm{DPI})$ 


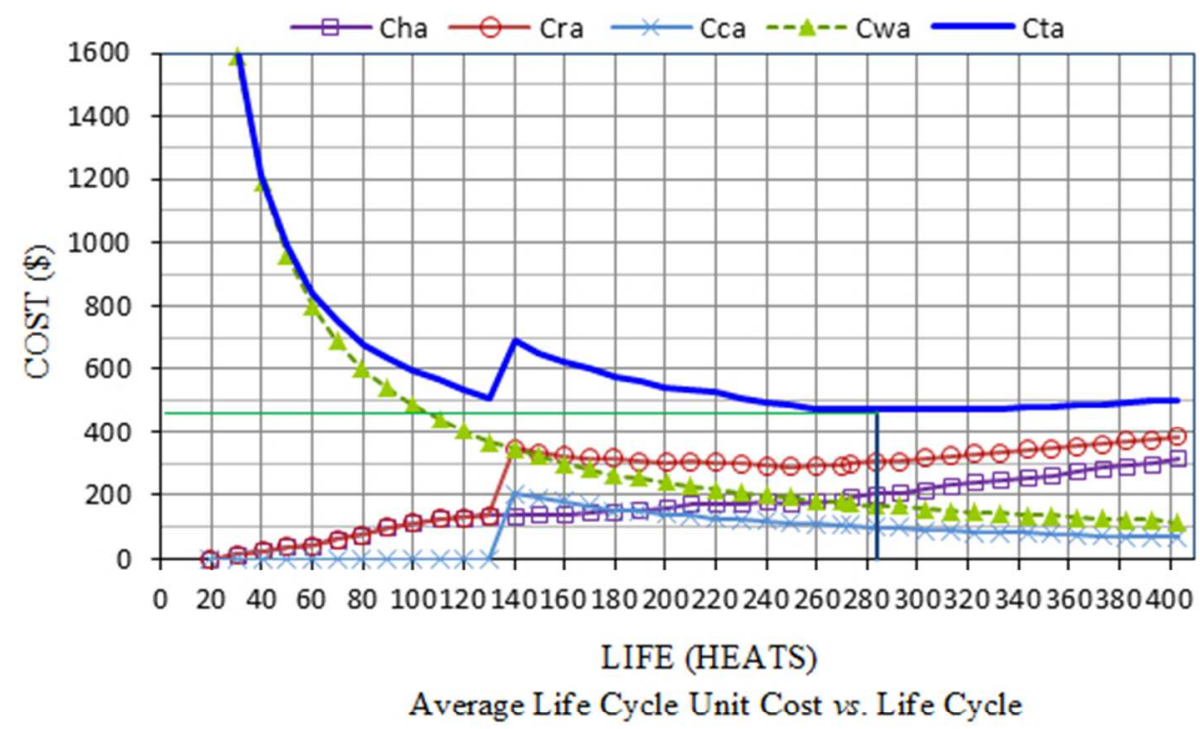

(a) With cold repair

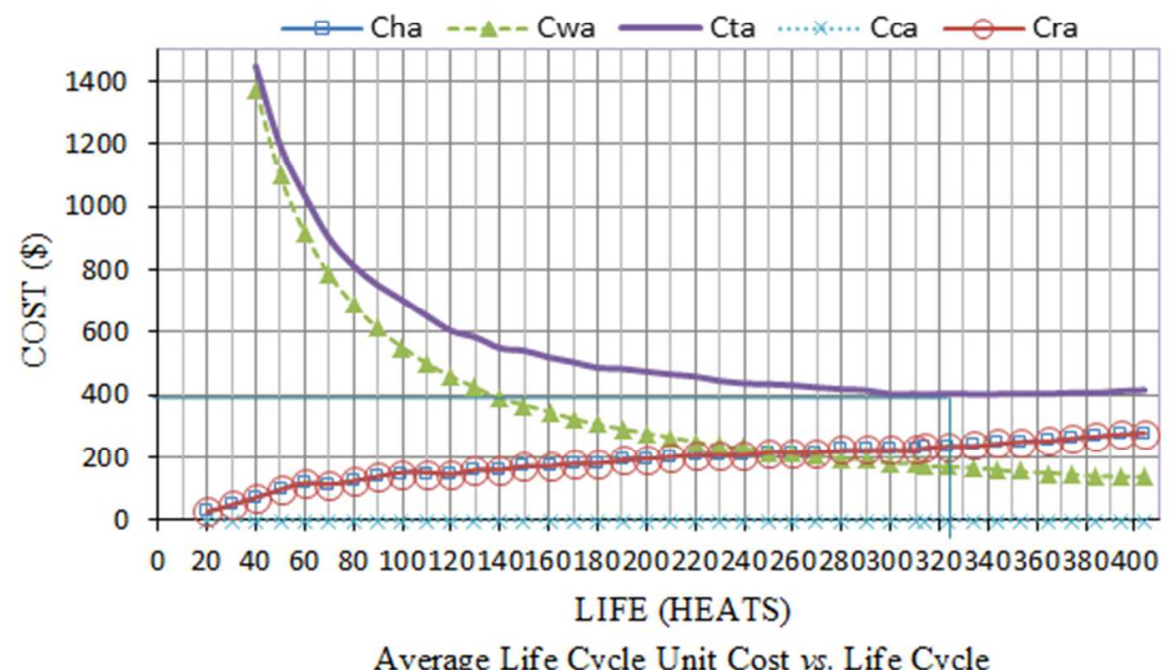

Average Life Cycle Unit Cost vs. Life Cycle

(b) Without cold repair

Figure 6 Determining the optimum number of replacement w/o using cold repair $152 \times 193 \mathrm{~mm}(96 \times 96 \mathrm{DPI})$ 
Table 1 Formulation of the optimum replacement model

\begin{tabular}{|c|c|c|c|c|c|c|c|c|}
\hline \multicolumn{4}{|c|}{ Finalized Input Period Variables } & \multicolumn{2}{|c|}{$\begin{array}{c}\text { Evaluation } \\
\text { Variables }\end{array}$} & $\begin{array}{l}\text { Decision } \\
\text { Variable }\end{array}$ & $\begin{array}{l}\text { Decision } \\
\text { Criterion } \\
\end{array}$ & $\begin{array}{l}\text { Optimum } \\
\text { Solution }\end{array}$ \\
\hline 1 & 2 & 3 & 4 & $5=3+4$ & 6 & $7=6 / 1$ & 8 & 9 \\
\hline $\begin{array}{c}\text { Service } \\
\text { Life or } \\
\text { Periods } \\
\text { (heats) }\end{array}$ & $\begin{array}{c}\text { Replac- } \\
\text { ement } \\
\text { Cost } \\
(\$)\end{array}$ & $\begin{array}{c}\text { Hot } \\
\text { Repair } \\
\text { Cost } \\
(\$)\end{array}$ & $\begin{array}{c}\text { Cold } \\
\text { Repair } \\
\text { Cost } \\
(\$)\end{array}$ & $\begin{array}{c}\text { Repair } \\
\text { Cost } \\
\text { hot \& } \\
\text { cold } \\
(\$)\end{array}$ & $\begin{array}{c}\text { Cumulative } \\
\text { Total } \\
\text { Cost } \\
(\$)\end{array}$ & $\begin{array}{c}\text { Average } \\
\text { Total } \\
\text { Cost } \\
(\$)\end{array}$ & $\begin{array}{l}\text { True } \\
\text { or } \\
\text { False }\end{array}$ & $\begin{array}{l}\text { Yes } \\
\text { or } \\
\text { No }\end{array}$ \\
\hline (i) & $\mathrm{Cw}_{(\mathrm{i})}$ & $\operatorname{Chp}_{(i)}$ & $\mathrm{Ccp}_{(\mathrm{i})}$ & $\operatorname{Crp}_{(\mathrm{i})}$ & $\mathrm{Ct}_{(\mathrm{i})}$ & $\mathrm{Cta}_{(\mathrm{i})}$ & $\begin{array}{l}\mathrm{Cta}_{(\mathrm{i}+1)} \geq \\
\mathrm{Cta}_{(\mathrm{i})}\end{array}$ & $\cdots$ \\
\hline$(\mathrm{i})=1$ & $\mathrm{CWwp}_{(1)}$ & $\begin{array}{c}\text { Chp }_{(1)} \\
=\mathbf{0}\end{array}$ & $\begin{array}{c}\operatorname{Ccp}_{(1)} \\
=0\end{array}$ & $\begin{array}{c}\operatorname{Crp}_{(1)} \\
=\mathbf{0}\end{array}$ & $\begin{array}{l}\mathrm{Ct}_{(1)}= \\
\mathrm{CW}_{(1)}\end{array}$ & $\begin{array}{c}\mathrm{Cta}_{(1)}= \\
\mathrm{Cw}_{(1)} / \mathrm{H}_{(1)}\end{array}$ & False & No \\
\hline (i) $=\mathbf{2}$ & $\mathbf{0}$ & $\mathrm{Chp}_{(2)}$ & $\operatorname{Ccp}_{(2)}$ & $\begin{array}{c}\operatorname{Crp}_{(2)}= \\
\operatorname{Chp}_{(2)} \\
+ \\
\operatorname{Ccp}_{(2)}\end{array}$ & $\begin{array}{c}\mathrm{Ct}_{(2)}= \\
\mathrm{Ct}_{(1)} \\
+ \\
\mathrm{Crp}_{(2)}\end{array}$ & $\begin{array}{c}\mathrm{Cta}_{(2)}= \\
\mathrm{Ct}_{(2)} / \mathrm{H} \\
(2)\end{array}$ & False & No \\
\hline .. & .. & .. & .. & .. &.. & .. & .. & .. \\
\hline (i) & $\mathbf{0}$ & $\operatorname{Chp}_{(\mathrm{i})}$ & $\mathrm{Ccp}_{(\mathrm{i})}$ & $\begin{array}{c}\operatorname{Crp}_{(\mathrm{i})}= \\
\operatorname{Chp}_{(\mathrm{i})} \\
+ \\
\operatorname{Ccp}_{(\mathrm{i})}\end{array}$ & $\begin{array}{c}\mathrm{Ct}_{(\mathrm{i})}= \\
\mathrm{Ct}_{(\mathrm{i}-1)} \\
+ \\
\mathrm{Crp}_{(\mathrm{i})}\end{array}$ & $\begin{array}{c}\mathrm{Cta}_{(\mathrm{i})}= \\
\mathrm{Ct}_{(\mathrm{i})} / \mathrm{H}_{(\mathrm{i})}\end{array}$ & False & No \\
\hline .. & .. &.. & .. & .. &.. & .. & .. & .. \\
\hline (i) $=\mathbf{k}$ & 0 & $\mathrm{Chp}_{(\mathrm{k})}$ & $\mathrm{Ccp}_{(\mathrm{k})}$ & $\begin{array}{c}\operatorname{Crp}_{(\mathrm{k})}= \\
\operatorname{Chp}_{(\mathrm{k})} \\
+ \\
\operatorname{Ccp}_{(\mathrm{k})}\end{array}$ & $\begin{array}{c}\mathrm{Ct}_{(\mathrm{k})}= \\
\mathrm{Ct}_{(\mathrm{i}-1)} \\
+ \\
\mathrm{Crp}_{(\mathrm{k})}\end{array}$ & $\begin{array}{c}\mathrm{Cta}_{(\mathrm{k})}= \\
\mathrm{Ct}_{(\mathrm{k})} / \mathrm{H} \\
(\mathrm{k})\end{array}$ & True & Yes \\
\hline
\end{tabular}


Table 2 Identifying variables and defining the repair limit

\begin{tabular}{|c|c|c|c|c|c|c|c|}
\hline \multicolumn{3}{|c|}{ Model Indication Variables } & \multicolumn{2}{|c|}{$\begin{array}{c}\text { Operation Life } \\
\text { Variables } \\
\end{array}$} & \multicolumn{2}{|c|}{$\begin{array}{c}\text { Model Cost } \\
\text { Variables } \\
\end{array}$} & \multirow{2}{*}{$\begin{array}{c}\text { Decision } \\
\text { Variable } \\
\text { Remaining } \\
\text { Age Value } \\
\text { (\$) }\end{array}$} \\
\hline $\begin{array}{l}\text { Maximum } \\
\text { gunning per } \\
\text { period (ton) }\end{array}$ & \begin{tabular}{|} 
Maximum \\
hot repair cost \\
per period \\
$(\$)$
\end{tabular} & $\begin{array}{r}\text { Optimum } \\
\text { cycle } \\
\text { length } \\
\text { (heats) }\end{array}$ & $\begin{array}{l}\text { Gunning } \\
\text { per period } \\
\text { (ton) }\end{array}$ & $\begin{array}{l}\text { Lining } \\
\text { service } \\
\text { length } \\
\text { (heats) }\end{array}$ & $\begin{array}{r}\text { Cold } \\
\text { repair } \\
\text { cost } \\
(\$)\end{array}$ & $\begin{array}{c}\text { Replacement } \\
\text { cost } \\
(\$)\end{array}$ & \\
\hline$\overline{\operatorname{Gpmax}_{(\mathrm{t})}}$ & $\operatorname{Chpmax}_{(\mathrm{t})}$ & 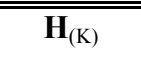 & $\bar{G} \mathbf{G p}_{(\mathrm{i})}$ & 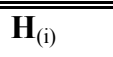 & $\mathbf{C} \mathbf{C c}_{(\mathrm{i})}$ & $\overline{\mathbf{C}} \mathbf{C \mathbf { w } _ { ( \mathrm { t } ) }}$ & 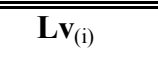 \\
\hline
\end{tabular}

Decision criterion for assessing cold repair limit is $\quad \mathbf{G p}_{(\mathrm{i})} \geq \operatorname{Gpmax}_{(\mathrm{t})}$

The Remaining Age Value is

The Repair limit is determined by

$\mathbf{L v}_{(\mathrm{i})}=\mathbf{C} \mathbf{w}_{(\mathrm{t})} \times\left(\mathbf{H}_{(\mathrm{K})}-\mathbf{H}_{(\mathrm{i})}\right) / \mathbf{H}_{(\mathrm{K})}$

or directly by,

$\mathrm{CRL}_{(\mathrm{i})}=\mathrm{Lv}_{(\mathrm{i})}-\mathrm{Chpmax}_{(\mathrm{t})}$

$\mathrm{CRL}_{(\mathrm{i})}=\mathbf{C w}_{(\mathrm{t})} \times\left(\mathbf{H}_{(\mathrm{K})}-\mathbf{H}_{(\mathrm{i})}\right) / \mathbf{H}_{(\mathrm{K})}-\mathrm{Chpmax}_{(\mathrm{t})}$

Table 3 Setting the decision criteria

\begin{tabular}{cccccc}
\hline \hline Life & $\begin{array}{c}\text { Remaining Age } \\
\text { Value }\end{array}$ & $\begin{array}{c}\text { Cold Repair } \\
\text { Cost }\end{array}$ & $\begin{array}{c}\text { Cold Repair } \\
\text { Limit }\end{array}$ & Criterion & Decision \\
\hline$(\mathrm{i})$ & $\mathbf{L v}_{(\mathrm{i})}$ & $\mathbf{C c}_{(\mathrm{i})}$ & $\mathrm{CRL}_{(\mathrm{i})}$ & $\mathbf{C c}_{(\mathrm{i})} \geq \mathrm{CRL}_{(\mathrm{i})}$ & $\begin{array}{c}\text { Replace or } \\
\text { Repair }\end{array}$ \\
\hline$(1)$ & $\mathbf{L v}_{(1)}$ & $\mathbf{C c}_{(1)}=0$ & $\mathrm{CRL}_{(1)}$ & No & Repair \\
$(2)$ & $\mathbf{L v}_{(2)}$ & $\mathbf{C c}_{(2)}=0$ & $\mathrm{CRL}_{(2)}$ & No & Repair \\
$\vdots$ & $\vdots$ & $\vdots$ & $\vdots$ & $\vdots$ & $\vdots$ \\
$(\mathrm{f})$ & $\mathbf{L v}_{(\mathrm{f})}$ & $\mathbf{C c}_{(\mathrm{f})}=$ value & $\mathrm{CRL}_{(\mathrm{f})}$ & Yes & Replace \\
\hline
\end{tabular}

Cold repair is applied as long as $\mathrm{CRL}_{(\mathrm{f})} \geq \mathbf{C c}_{(\mathrm{f})}$, otherwise, there is no replacement at point (f). 
Table 4 Sensitivity analysis provided by the model to show advantages and limitations for decisions

\begin{tabular}{|c|c|c|c|c|c|c|c|c|c|c|c|c|c|c|}
\hline $\begin{array}{c}\text { Life } \\
\text { cycle } \\
\text { Sample }\end{array}$ & $\begin{array}{c}\text { Material } \\
\text { type }\end{array}$ & $\begin{array}{c}\begin{array}{c}\text { Replacement } \\
\text { cost }\end{array} \\
\$\end{array}$ & $\begin{array}{c}\text { Hot repair } \\
\text { cost per } \\
\text { interval } \\
\$\end{array}$ & $\begin{array}{c}\text { Hot repair } \\
\text { cost } \\
\$\end{array}$ & $\begin{array}{c}\text { Cold repair } \\
\text { cost } \\
\$\end{array}$ & $\begin{array}{c}\text { Cold repair } \\
\text { application } \\
\text { interval } \\
\text { heats }\end{array}$ & $\begin{array}{c}\text { Optimum } \\
\text { life } \\
\text { heats }\end{array}$ & $\begin{array}{c}\text { Optimum } \\
\text { LCC per } \\
\text { heat } \\
\$\end{array}$ & $\begin{array}{c}\text { Optimum } \\
\text { LCC/ton of } \\
\text { liquid steel } \\
\$\end{array}$ & $\begin{array}{c}\text { Actual } \\
\text { operation } \\
\text { life } \\
\text { heats }\end{array}$ & $\begin{array}{c}\text { Actual } \\
\text { LCC per } \\
\text { heat } \\
\$\end{array}$ & $\begin{array}{c}\text { Actual } \\
\text { LCC/ton of } \\
\text { liquid steel } \\
\$\end{array}$ & $\begin{array}{l}\text { Loss beyond } \\
\text { opyimum point } \\
\text { per heat } \\
\$\end{array}$ & $\begin{array}{c}\text { Average } \\
\text { annual } \\
\text { loss } \\
\$\end{array}$ \\
\hline 1 & A & 50504 & 2310.38 & 73932 & 28576 & 140 & 320 & \begin{tabular}{|l|}
478.163 \\
\end{tabular} & 5.31 & 400 & 501.5 & 5.57 & -23.34 & -58342.50 \\
\hline 2 & A & 50504 & 2542.47 & 81359 & 28576 & 150 & 320 & \begin{tabular}{|l|}
501.372 \\
\end{tabular} & 5.57 & 330 & 503.45 & 5.59 & -2.08 & -5195.00 \\
\hline 3 & A & 50504 & 2762.70 & 102220 & 28576 & 140 & 370 & 490 & 5.44 & 330 & 498.74 & 5.54 & -8.74 & -21850.00 \\
\hline 4 & A & 50504 & 2358.75 & 75480 & 28576 & 150 & 320 & 483 & 5.37 & 330 & 483.83 & 5.38 & -0.83 & -2075.00 \\
\hline Average & A & 50504 & 2493.57 & \begin{tabular}{|l|}
83247.75 \\
\end{tabular} & 28576 & 145 & 333 & 488.1338 & 5.42 & 348 & 496.88 & 5.52 & -8.75 & -21865.62 \\
\hline 5 & $B$ & 54840 & 2476.00 & 64376 & $\ldots$. & $\ldots$. & 260 & \begin{tabular}{|l|}
458.523 \\
\end{tabular} & 5.09 & 240 & 462.88 & 5.14 & -4.36 & -10892.50 \\
\hline 6 & $B$ & 54840 & 2344.96 & 56279 & $\ldots$. & $\ldots$. & 240 & \begin{tabular}{|l|}
462.996 \\
\end{tabular} & 5.14 & 240 & 462.996 & 5.14 & 0.00 & 0.00 \\
\hline 7 & $B$ & 54840 & 2292.00 & 68760 & $\ldots$ & $\ldots$ & 300 & 412 & 4.58 & 310 & 416 & 4.62 & -4.00 & -10000.00 \\
\hline 8 & $B$ & 54840 & 2226.25 & 71240 & $\ldots$. & $\ldots$ & 320 & 394.9 & 4.39 & 320 & 394.9 & 4.39 & 0.00 & 0.00 \\
\hline \begin{tabular}{|l|} 
Average \\
\end{tabular} & $B$ & 54840 & 2334.80 & \begin{tabular}{|l|}
65163.75 \\
\end{tabular} & $\ldots$ & $\ldots$ & 280 & \begin{tabular}{|l|}
432.1048 \\
\end{tabular} & 4.80 & 278 & 434.194 & 4.82 & -2.09 & -5223.12 \\
\hline 9 & C & 47691 & 1860.60 & 27909 & $\ldots$. & $\ldots$. & 150 & 504 & 5.60 & 120 & 541.97 & 6.02 & -37.97 & -94925.00 \\
\hline 10 & C & 47691 & 4143.07 & 58003 & 28576 & 140 & 140 & 463 & 5.14 & 270 & 476.71 & 5.30 & -13.71 & -34275.00 \\
\hline 11 & C & 47691 & 4607.75 & 55293 & 28576 & 120 & 120 & 572 & 6.36 & 210 & 575.5 & 6.39 & -3.50 & -8750.00 \\
\hline 12 & C & 47691 & 1945.45 & 38909 & $\ldots$ & $\ldots$ & 200 & 433 & 4.81 & 170 & 442.8 & 4.92 & -9.80 & -24500.00 \\
\hline Average & C & 47691 & 3139.22 & 45028.5 & $\ldots$ & $\ldots$ & 153 & 493 & 5.48 & 192 & 509.245 & 5.66 & -16.25 & -40612.50 \\
\hline
\end{tabular}


Table 5 Output values of the model for decision criteria and optimum status

\begin{tabular}{|c|c|c|c|c|c|}
\hline \multirow[t]{2}{*}{ Parameter } & \multirow[t]{2}{*}{ Unit } & \multicolumn{4}{|c|}{ Material Suppliers } \\
\hline & & \multicolumn{2}{|c|}{ Supplier-A } & Supplier-B & Supplier-C \\
\hline Replacement Cost & $\$$ & \multicolumn{2}{|c|}{175,490} & 161,614 & 152,613 \\
\hline Cold Repair Cost & $\$$ & \multicolumn{2}{|c|}{91,446} & 91,446 & 91,446 \\
\hline Maximum Gunning & Ton & \multicolumn{2}{|c|}{5.20} & 6.0 & 5.50 \\
\hline Hot Repair Period Length & Heats & \multicolumn{2}{|c|}{10} & 10 & 10 \\
\hline Max. Hot Repair Cost per Period & $\$$ & \multicolumn{2}{|c|}{13,682} & 14,007 & 15,907 \\
\hline Optim. EAF Working Lining Life & Heats & \multicolumn{2}{|c|}{278} & 319 & 229 \\
\hline Cold Repair Limit & Heats & \multicolumn{2}{|c|}{120 -to-130 } & 110 -to-120 & 80 -to-90 \\
\hline Cold Repair Actual Application & --- & \multicolumn{2}{|c|}{ Not Feasible } & Feasible & Feasible \\
\hline Total Cost per Heat (Cta) & $\$$ & \multicolumn{2}{|c|}{1,426} & 1,544 & 1,652 \\
\hline Total Cost per Ton of Liquid Steel & $\$$ & \multicolumn{2}{|c|}{15.6} & 16.8 & 16.8 \\
\hline Expense in Terms of Use & --- & \multicolumn{2}{|c|}{ Cheapest } & Moderate & Most Expensive \\
\hline Priority for Use & --- & \multicolumn{2}{|c|}{ First } & Second & Third \\
\hline Optimum Life Achievement & --- & \multicolumn{2}{|c|}{$\begin{array}{c}\text { Always } \\
\text { achieved, or } \\
\text { over passed }\end{array}$} & $\begin{array}{c}\text { Rarely } \\
\text { achieved but } \\
\text { close to }\end{array}$ & $\begin{array}{l}\text { Never achieved } \\
\text { and much less }\end{array}$ \\
\hline $\begin{array}{l}\text { Priority of Safety Base on Optimum } \\
\text { Life Achievement }\end{array}$ & --- & \multicolumn{2}{|c|}{$\begin{array}{l}\text { Highly safe } \\
\text { since it } \\
\text { overpass }\end{array}$} & $\begin{array}{l}\text { Moderately } \\
\text { safe since it } \\
\text { is close to }\end{array}$ & $\begin{array}{l}\text { Low safety } \\
\text { since it never } \\
\text { reaches }\end{array}$ \\
\hline $\begin{array}{l}\text { Total Annual Cost based on use of } \\
\text { each suppliers material alone }\end{array}$ & $\$$ & \multicolumn{2}{|c|}{$5,436,058$} & $5,887,760$ & $6,298,710$ \\
\hline \multicolumn{6}{|c|}{ Matrix for Annual Savings or Losses based on Optimum Life Criteria of one EAF } \\
\hline Material Supplier & \multicolumn{2}{|c|}{ Supplier-A } & \multicolumn{2}{|c|}{ Supplier-B } & Supplier-C \\
\hline Supplier-A & & \multicolumn{2}{|c|}{$-\$ 451,703$} & $-\$ 862,653$ \\
\hline Supplier-B & \multicolumn{2}{|c|}{$\$ 862,653$} & \multicolumn{2}{|c|}{------- } & $-\$ 410,950$ \\
\hline Supplier-C & \multicolumn{2}{|c|}{$\$ 862,653$} & \multicolumn{2}{|c|}{$\$ 410,950$} & -------- \\
\hline $\begin{array}{l}\text { Result by Comparing Actual life to } \\
\text { Optimum Life }\end{array}$ & \multicolumn{2}{|c|}{$\begin{array}{l}\text { High Savings } \\
\text { by not over } \\
\text { passing } \\
\text { optimum life }\end{array}$} & \multicolumn{2}{|c|}{$\begin{array}{l}\text { Almost zero } \\
\text { losses by being } \\
\text { close to achieving } \\
\text { optimum life }\end{array}$} & $\begin{array}{c}\text { High losses } \\
\text { because optimum } \\
\text { life is usually not } \\
\text { achieved }\end{array}$ \\
\hline
\end{tabular}

